\title{
INTERFACING A SOLAR PHOTOVOLTAIC SYSTEM WITH THE NATIONAL ELECTRICITY GRID IN MALTA
}

\author{
Charles Iskander \& Edward Scerri \\ Institute for Energy Technology, University of Malta \\ Triq il-Port Ruman, Marsaxlokk. ZTN 09, Malta \\ Phone: $++(356)$ 650675/612249, Fax: $++(356) 650615$, e-mail: iskander@global.net.mt
}

\begin{abstract}
A $1.8 \mathrm{kWp}$ grid-connected solar photovoltaic system is being monitored at the Institute for Energy Technology, since June 1996. The average performance ratio for 22 months of operation was found to be 0.715 , which translates to a final yield of $3.44 \mathrm{kWh} / \mathrm{kWp} / \mathrm{day}$. The average final efficiency was found to be $7.6^{\%}$. These values exclude the month of October 1997, during which the system was not operating.
\end{abstract}

Problems encountered. relating to the interface between the electric utility grid and the $P I^{r}$ system are discussed. 1998 Elsevier Science Ltd. All rights reserved.

\section{KEYWORDS}

photovoltaic; grid-connected; inverter; performance ratio; yield.

\section{INTRODUCTION}

A $1.8 \mathrm{kWp}$ photovoltaic grid-connected system was installed in June 1996. It consisted of 30 Solarex MSX60 solar modules and an SMA PVWR 1800 S inverter, besides the other balance of system components. The sizing, construction and design of the monitoring system are described elsewhere [Iskander, June 1997]. This is the first system to be tested in Malta and the main aim is to gain experience from monitoring the performance of the system under local conditions so as to be able to implement the right technology in the right place and time. The Institute launched this project with the domestic consumers in mind. who presently use $30 \%$ of the electricity generated and are considered to be the major cause of peak loads. It is aimed that the results from this project will help produce relevant guidelines to install and safely run such systems in Malta.

\section{PRESENTATION OF RESULTS}

Figure 1. shows the average monthly in-plane solar radiation $(I G)$ and performance ratios $(P R)$ for the period June 1996 to March 1998, measured in accordance with the guidelines set by the Joint Research Centre, Ispra Establishment (Ispra, June 1996). 


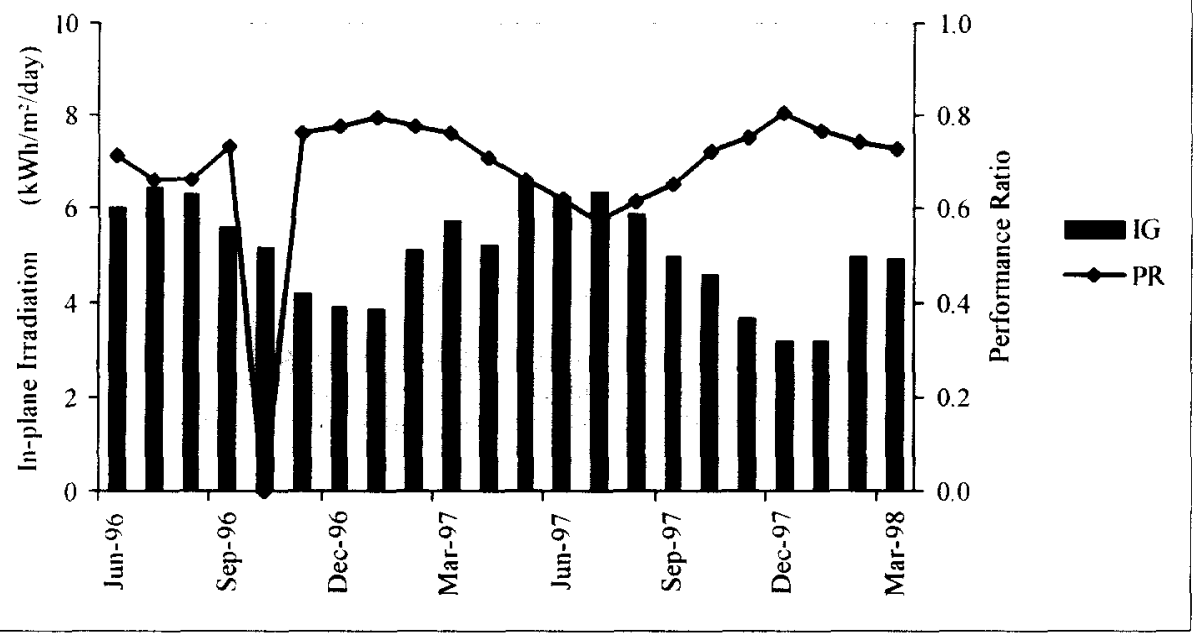

FIGURE 1: Plot of the mean in-plane solar global irradiation $(I G)$ and performance ratio $(P R)$ for the period June 1996 to March 1998.

\section{ANALYSIS OF RESULTS}

Two main operation gaps were encountered, namely, Sep.-Nov., 1996 and Jun.-Jul., 1997. The first failure was due to an indirect strike by lightning that caused a malfunction in the inverter. The inverter had to be sent back to the manufacturer for repairs. As a result. the system was not operating for 53 days. During the second year, the persistent high grid voltage prompted the inverter to shut down. This problem was solved by changing the EPROM with another one that had a higher voltage limit to suite the operating conditions in

Malta $(240$ V. a.c. $\pm 10 \%)$, rather than the original European limits of $230 \mathrm{~V}$, for which the inverter was designed. In turn. the system was idle for 50 days.

Figure 2, shows scatter diagrams of the normalised hourly array outputs versus the mean hourly in-plane radiation, for 4 different months. It can be concluded that the plant was operating at its maximum power generation, and this could be an indicator of the correct operation of the maximum power point tracker of the inverter

It can be seen for the month of August 1996, more clearly than in the other months, that there are 2 different slopes followed by the array output. In summer, the $P V$ array generates more power in the morning than in the afternoon. This behaviour is caused by the fact that the modules heat up and cool down slowly, thus causing the module efficiency to be higher in the morning.

l1 winter, this effect tends to decrease and sometimes reverse, since witb higher temperature gradients between the ambient and the array, the solar modules cool faster in the afternoon. An example is given in Figure 3. for 2 different sunny days in summer and winter. The percentage difference between moming and evening outputs is $\pm 15 \%$. 


\section{RESULTS OF MONITORING THE UTILITY GRID}

The voltage and frequency of the national electricity grid have been monitored during the operation of the inverter. Instantaneous voltage and frequency variations outside the allowable limits $i, e . \pm 10 \%$ for voltage readings and $\pm 1 \%$ for frequency values. have been occasionally noticed but this cannot be documented since

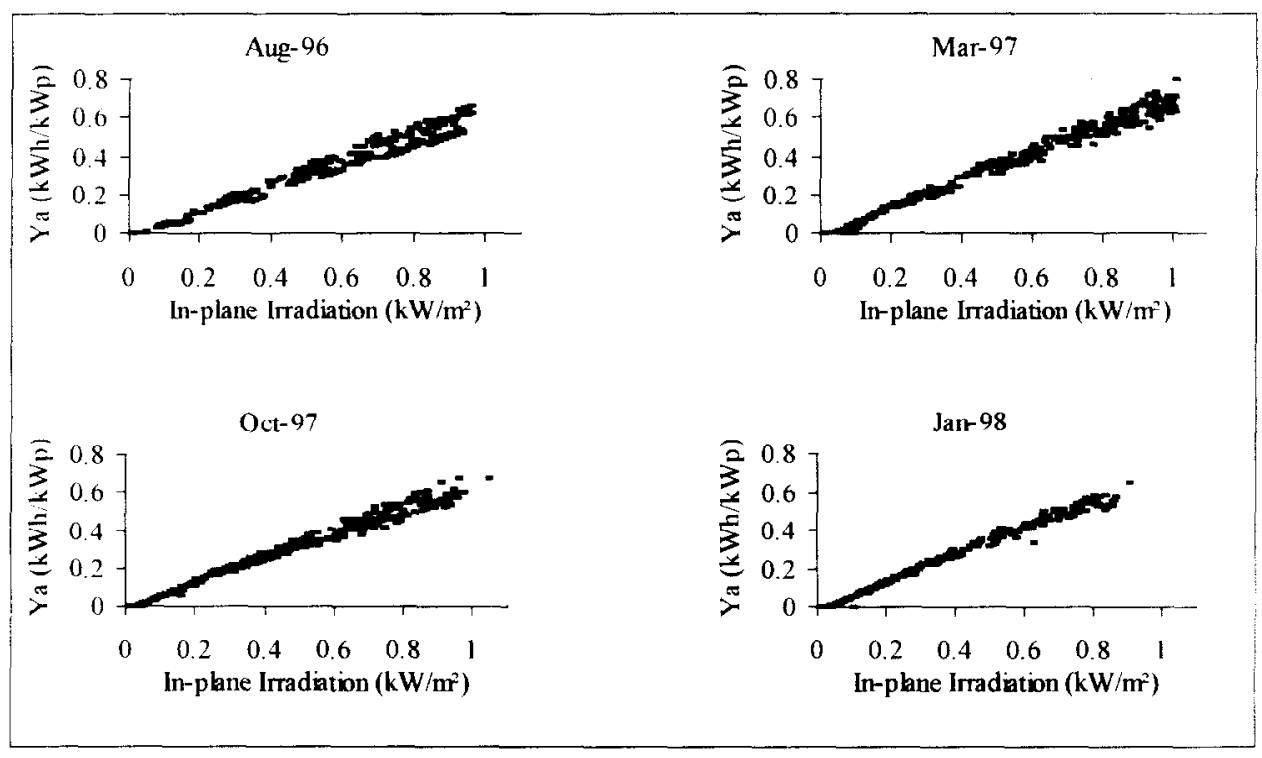

FIGURF 2: Plots of average hourly array yields against the in-plane radiation for 4 different months.

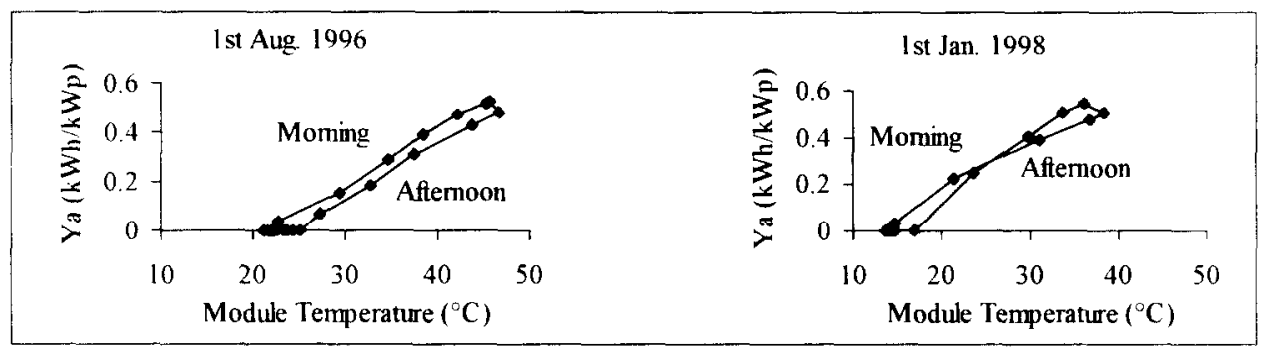

FIGURE 3: Hourly array yield versus the solar module temperature in August and January.

these instantaneous readings taken every 10 seconds are averaged over a 15 -minute interval. The variations do not persist for a long time and hence the 15-minute averages are well within the allowable limits, as seen in Figure 4.

Though the overall average frequency behaviour seems to be within the allowable limits, the voltage limits tend to vary continuously. In fact the upper voltage limit has been increasing, which prompts us to keep a close look on its future behaviour. In the event that such discrepancies continue, one has to consider the possibility of installing a voltage regulator to protect the inverter and maximise its useful operational time. 


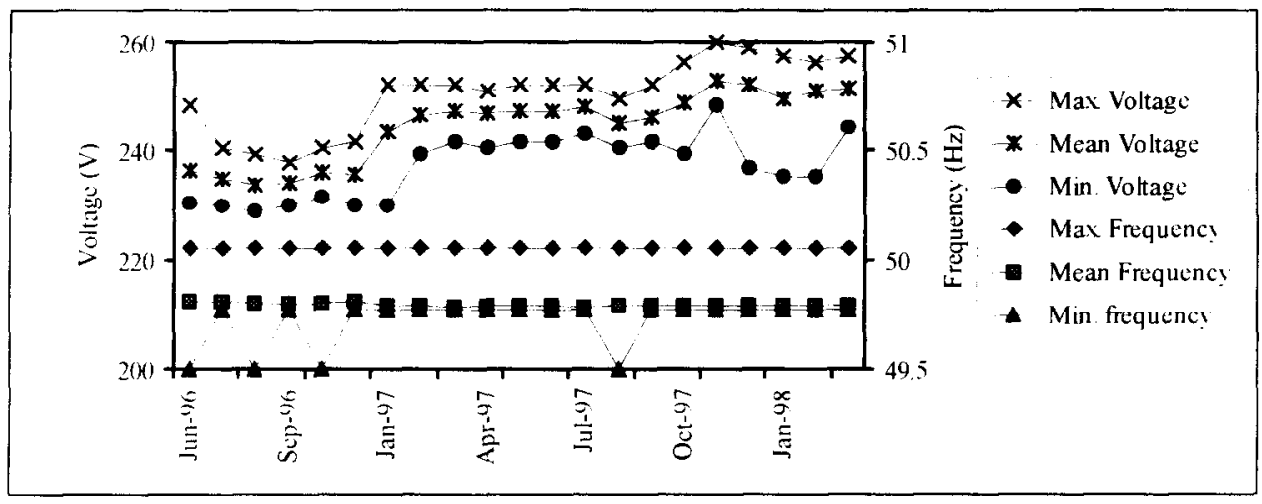

FIGURE 4 Mean 15-minute electricity grid voltage and frequency (June 1996 - March 1998).

\section{CONCLUSION}

The $1.8 \mathrm{kWp}$ solar photovoltaic grid-connected system has produced $3536 \mathrm{kWh}$ during 565 days of operation, which translates to an average of $6.25 \mathrm{kWh} /$ day. One-hundred and three days were lost when the inverter was not functioning. which brings the percentage operation time of the system down to $85 \%$

Such a $P l^{\prime}$ system would cover $70 \%$ of the consumption of an average family of 4 people in Malta, that consumes about $9 \mathrm{kWh}$ per day. Needless to say that it is wise to use a solar water heater to supply the hot water needs. thus saving on the electricity consumption even further. The extra electricity produced from the solar system can then be sold to the utility grid. The National Energy Legislation has still to be amended to allow grid-connection

\section{REFERENCES}

Iskander, C and Scerri, E. (Jun 1997), First-Hand Experience of Solar Photovoltaic Grid-connection in Malta, Proceedings of the 1tth European Photovoltaic Solar Energy Conference and Exhibition. Barcelona. Spain, 30th June - 4th July, 1997

Ispra. (June 1990), (inidelines for the Assessmen of Photovoltaic Plants, Document B. Issue 2, June 1990. Commission of the European Communities, Joint Research Centre - Ispra Establishment 